Research Journal of Applied Sciences, Engineering and Technology 16(5): 212-220, 2019

DOI:10.19026/ajms.16.5424

ISSN: 2040-7459; e-ISSN: 2040-7467

(C) 2019 Maxwell Scientific Publication Corp.

Submitted: May 29, 2019

Accepted: July 7, 2019

Published: December 15, 2019

\title{
Research Article \\ Comparative Accuracies of Fiber Bragg Grating Sensing Systems for Temperature Measurement
}

\author{
${ }^{1}$ Kanar R. Tariq, ${ }^{2}$ Riyam A. Johni and ${ }^{3}$ David I. Forsyth \\ ${ }^{1}$ Technical College of Informatics, Sulaimani Polytechnic University, Sulaimaniyah, KRG, Iraq \\ Software Engineering, Qaiwan International University-UTM Franchise, Sulaimaniyah, KRG, Iraq \\ ${ }^{2}$ Kurdistan Technical Institute, Sulaimaniyah, KRG, Iraq \\ ${ }^{3}$ Electrical/Electronic computer engineering lecturer, Henan Polytechnic University, No. 2001, \\ Shiji Road, Jiaozuo, Henan, P.R. China
}

\begin{abstract}
In this study, using state-of-the-art optical simulation software, we design, simulate and quantify the comparative accuracies of two types of FBG-based optical sensing systems: one is designed for lengthy, multiplexed multi-temperature measurements, the other for single-point measurements. Results and discussion are made to analyze the comparative performances, particularly in terms of linearity and accuracy.
\end{abstract}

Keywords: Grating, optical, sensing, system, temperature, wavelength

\section{INTRODUCTION}

A decade-and-a-half previously, the standard mechanism to measure physical and mechanical phenomena was usually with electrical sensors. Despite their ubiquity then, these sensors had several inherent limitations; such as transmission loss and susceptibility to electromagnetic interference (noise), which rendered their usage challenging and impractical to many applications (John Dakin, 1997; Culshaw, 1989; Joseph, 2005; Gerd, 2000). Various techniques and solutions then allowed researchers to overcome these problems by proposing new methods, such as changing the medium from electrical to light. Light was shown to have many advantages, due to its own inherent nature and was from then on used extensively in sensing using optical fiber media.

One area rapidly "spun-off" from optical fiber sensing became the ubiquitous use of Fiber Bragg Grating (FBG) sensors written into fiber. In this study, we simulate the use of FBGs to measure the physical change of temperature. We quantify the potential of two differing sensor systems incorporating FBGs. These types of sensor have great application value, especially in the area of distributed embedded sensing in materials used on "smart" structures - such as bridges, wind turbine blades, pipelines and dams.

The Fiber Bragg Grating has an operating principle close to that of a Fabry-Perot interferometer, or an intensity-based fiber optic sensor. They are a type of distributed Bragg reflector, constructed within a short segment of optical fiber, reflecting particular wavelengths of light but transmitting all others (Kersey et al., 1997; Kersey et al., 1993; Rao, 1997). The physical characteristics of a FBG typically exist inside a very short section (a few millimeters) of Single-Mode (SM) fiber. Bragg grating sensors are based on reflection and interference of multiple light beams traveling through the fiber, each being reflected by a small refractive index discontinuity in the grating (Othonos, 2000; Rao et al., 1997; Gebremichael et al., 2001).

The basic structure of a FBG is shown in Fig. 1. It is fabricated inside the core of the fiber optic cable and there are a number of methods for producing such intracore gratings into single mode fiber, as used in distributed Bragg grating sensors. The basic operating principle of a FBG is shown in Fig. 2. When a broadband light source beam is sent to interrogate a FBG, reflections from each segment of alternating refractive index interfere constructively, only for a specific wavelength of light called the Bragg wavelength, $\lambda_{b}$. This effectively causes the FBG to reflect a specific frequency of light, while transmitting all others. The Bragg wavelength, $\lambda_{b}$ is a function of the spacing between the gratings, $\Lambda$ with the effective refractive index, $n_{e}$ of the fiber core. The equation of the Bragg wavelength is shown in Eq. (1) below:

Corresponding Author: Kanar R. Tariq, Technical College of Informatics, Sulaimani Polytechnic University, Sulaimaniyah, KRG, Iraq

This work is licensed under a Creative Commons Attribution 4.0 International License (URL: http://creativecommons.org/licenses/by/4.0/). 


$$
\lambda_{b}=2 n_{e} \Lambda
$$

\section{DESIGN AND SIMULATION}

Figure 3 shows a practical array of FBG sensors. The working process here can simply be described as the following: a light source passes through a fiber optic coupler, which is then transmitted by fiber optic cabling in order to reach the FBG sensors one by one. The narrow spectrum that satisfies the Bragg condition in each case is then reflected back and occurs an offset value relative to its initial wavelength. This initial wavelength is the FBG center wavelength, which has not been influenced by the measurand (temperature). Based on Fig. 3, a similar FBG sensor array system was constructed using the Optsim Software. A single FBG sensor system was also created.

The model system for the single FBG sensor is shown in Fig. 4. It consists of a transmitter arm containing a Pseudo-Random-Bit-Sequence (PRBS) pattern generator, an electrical generator, an electrical filter, an external modulator and a Continuous Wave (CW) laser source. The receiver system consists of FBG one and FBG two and was embedded in the receiver block component itself. The simulation process was first done for the single FBG sensor. This was calibrated with temperature values from $0^{\circ} \mathrm{C}$ to $320^{\circ} \mathrm{C}$, the reflected central FBG wavelength being $1550 \mathrm{~nm}$. The wavelength spectrum for the light source is shown in Fig. 5.

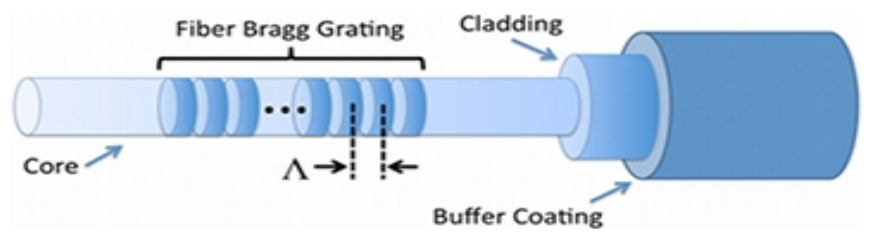

Fig. 1: Basic structure of a FBG (Gerd, 2000)

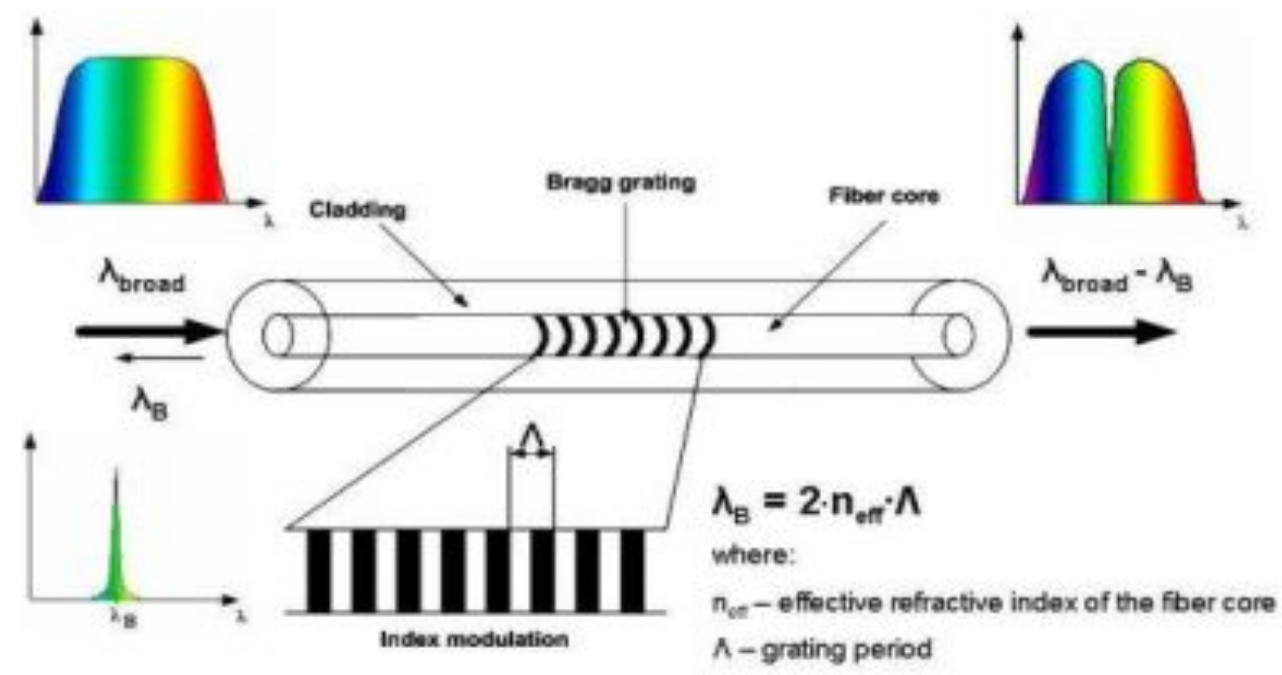

Fig. 2: Basic principle of a FBG (Kersey et al., 1997)

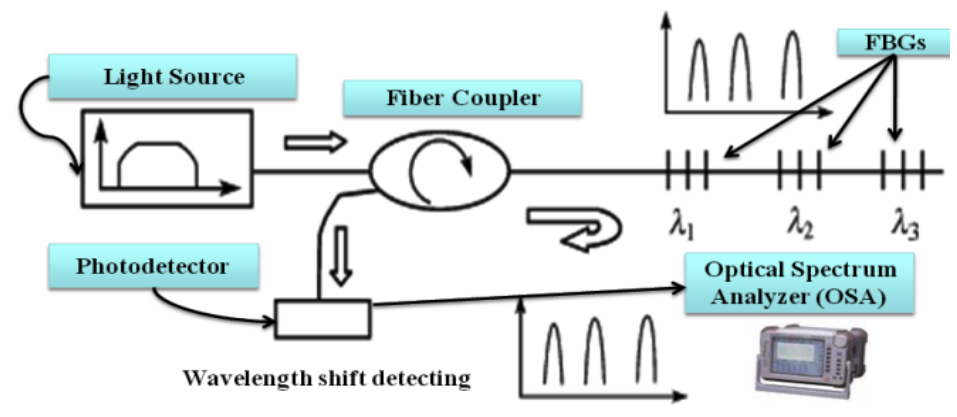

Fig. 3: System design of FBG sensor array (Kersey et al., 1993) 


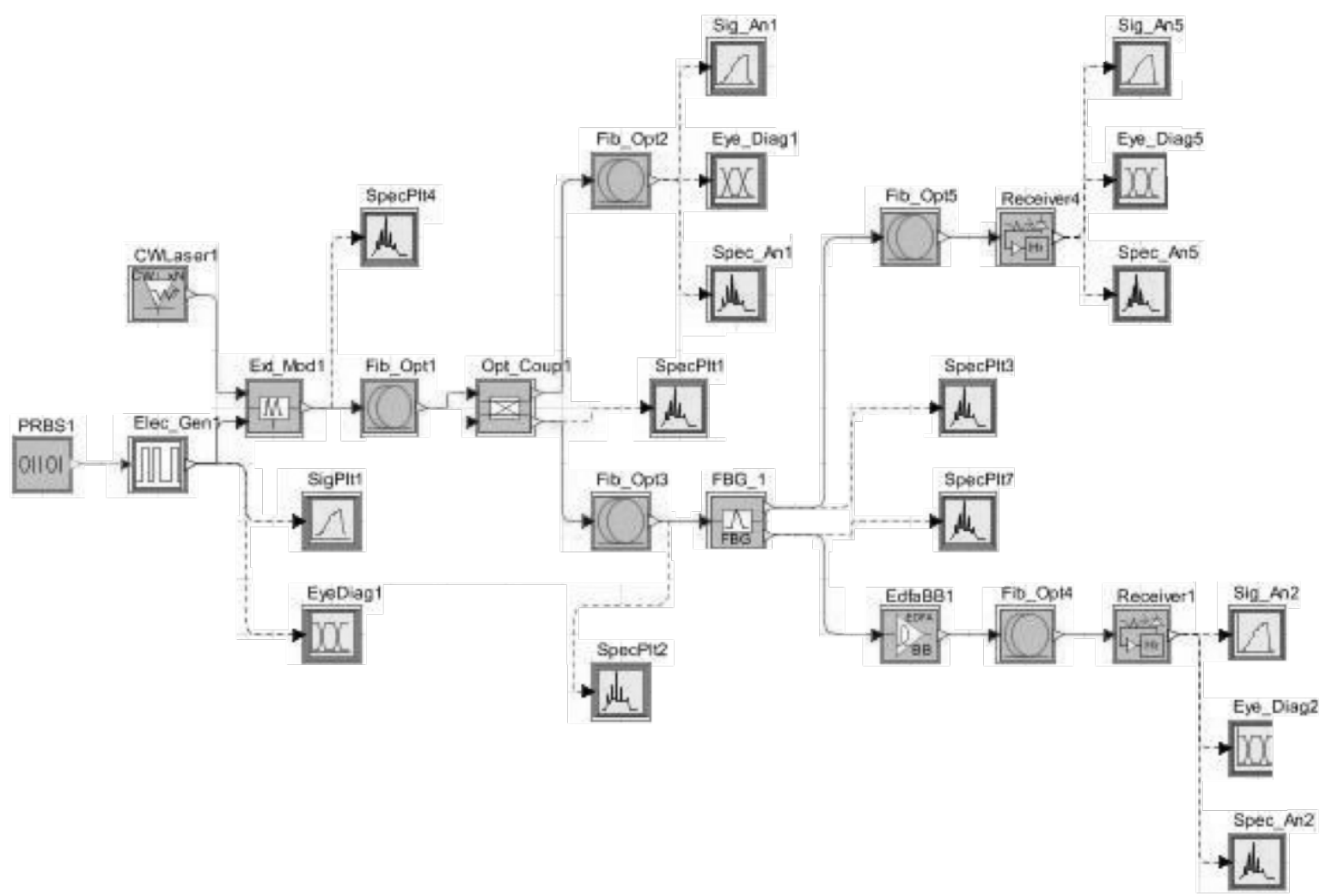

Fig. 4: Single FBG sensor

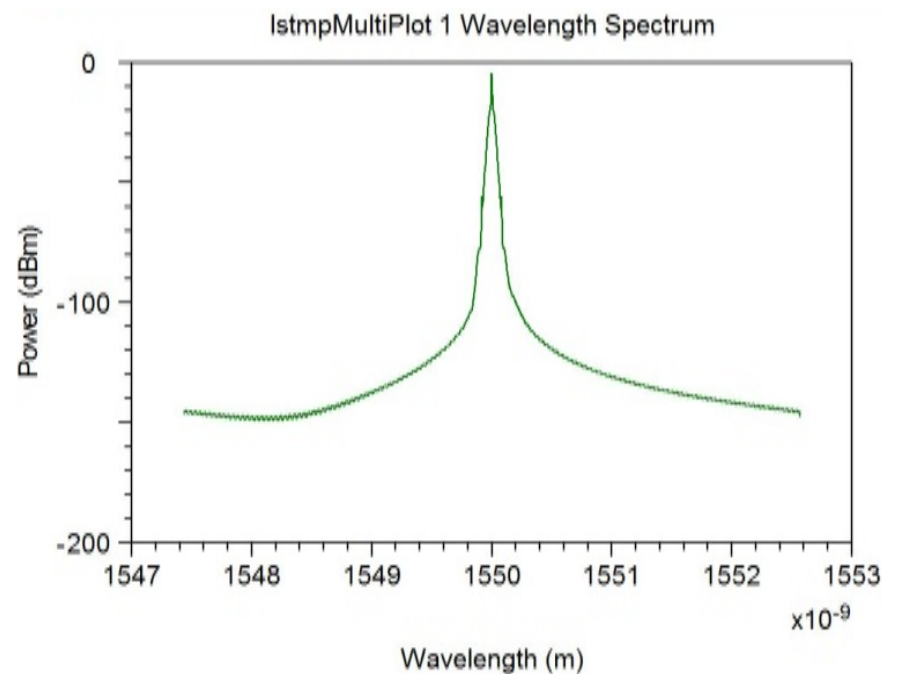

Fig. 5: Wavelength spectrum of transmitter

Figure 6 and 7 show the spectrum for the transmitted and reflected wavelengths respectively, at a randomly chosen $40^{\circ} \mathrm{C}$ value of temperature. Figure 8 shows the array-based FBG sensing system created, consisting of 6 FBG arrays connected in series. In this type of sensing system we can detect temperature both at multiple and at selective points. A type of wavelength division multiplexing approach was adopted, with each FBG given a different value of Bragg wavelength, as listed in Table 1. The two model systems were essentially of the same construction. However, the FBG sensor array system will have some attenuation and distortion losses, which would cause a little degradation in the peak power. Hence, the use of the amplifier in this set-up. The transmitted wavelengths were detected at receiver one and the 
Res. J. Appl. Sci. Eng. Technol., 16(5): 212-220, 2019

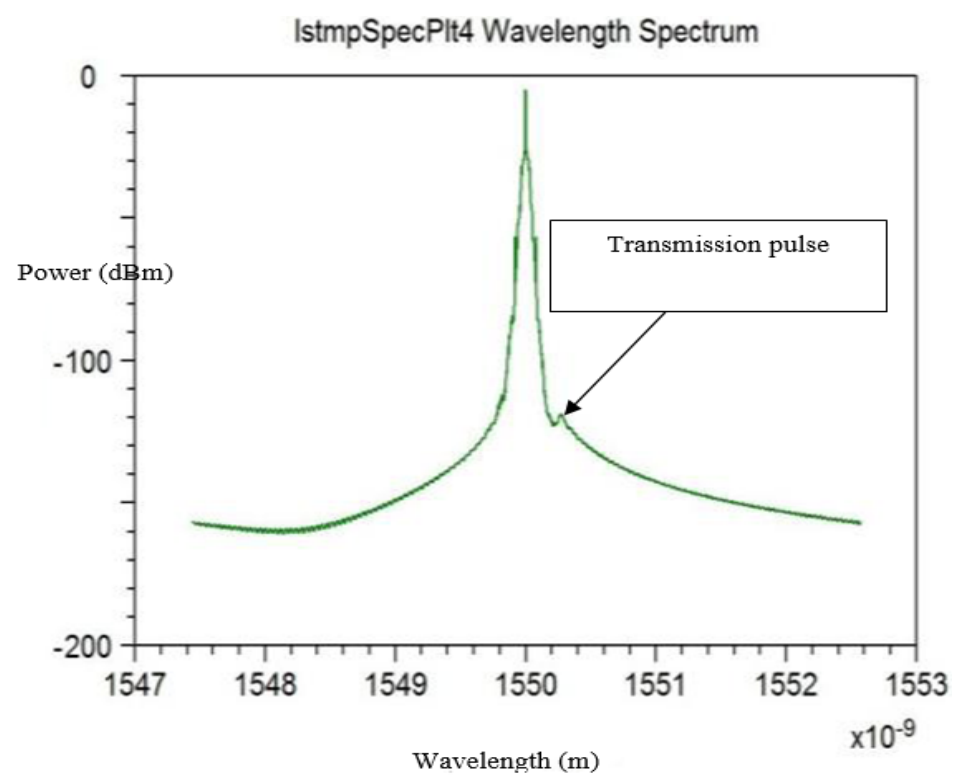

Fig. 6: Transmission pulse at temperature $40^{\circ} \mathrm{C}$

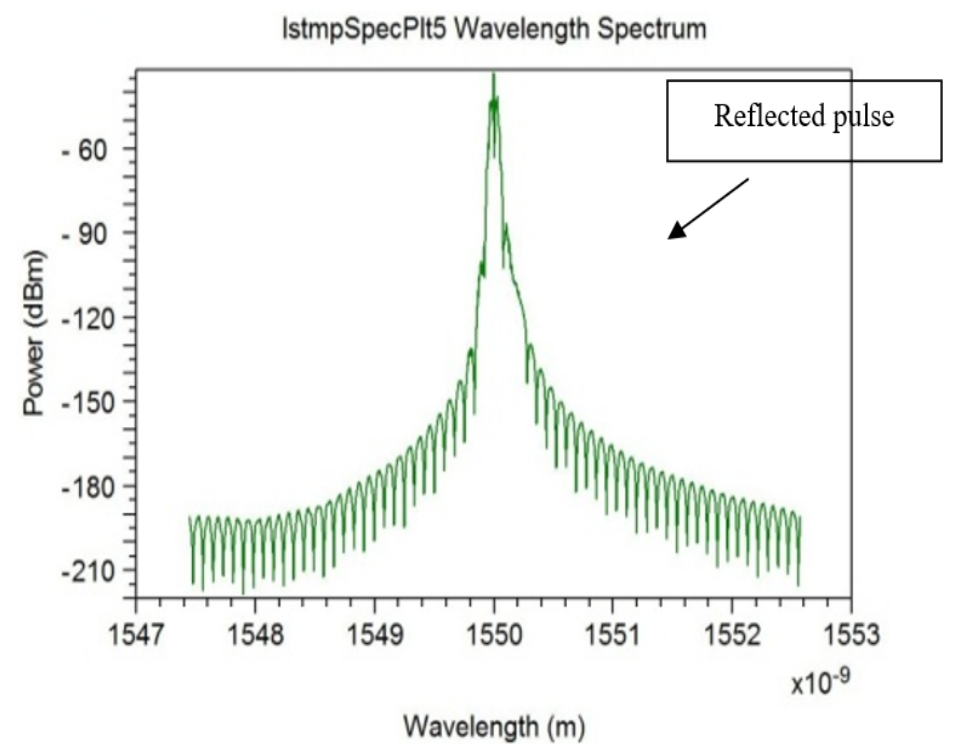

Fig. 7: Reflected pulse at temperature $40^{\circ} \mathrm{C}$

$\underline{\text { Table 1: Bragg wavelengths }}$

\begin{tabular}{lll}
\hline Type of FBG & Grating Period, $\Lambda$ & $\begin{array}{l}\text { The value of bragg } \\
\text { wavelength }(\mathrm{nm})\end{array}$ \\
\hline FBG 1 & 0.5450 & 1548.0 \\
FBG 2 & 0.5452 & 1548.5 \\
FBG 3 & 0.5453 & 1549.0 \\
FBG 4 & 0.5455 & 1549.5 \\
FBG 5 & 0.5457 & 1550.0 \\
FBG 6 & 0.5459 & 1550.5 \\
\hline
\end{tabular}

reflected wavelengths were detected at receiver two. Figure 9 and 10 show the wavelength spectrum for the transmitted and reflected wavelengths respectively for a $40^{\circ} \mathrm{C}$ value of temperature using the array, which compliment Fig. 6 and 7.

\section{RESULTS AND DISCUSSION}

The value of Bragg wavelength recorded was collated together with the temperature values in each case. The graphing software used obtained regression values of linearity and sensitivity. These values were then used to determine the performances of both modeled systems.

We used OptSim software to design and simulate the two types of FBG-based sensing systems, which are single FBG sensor and an array type, then we used an array one to detect and measure the temperature at some selective points and multiple points to clarify the performance for both types. 


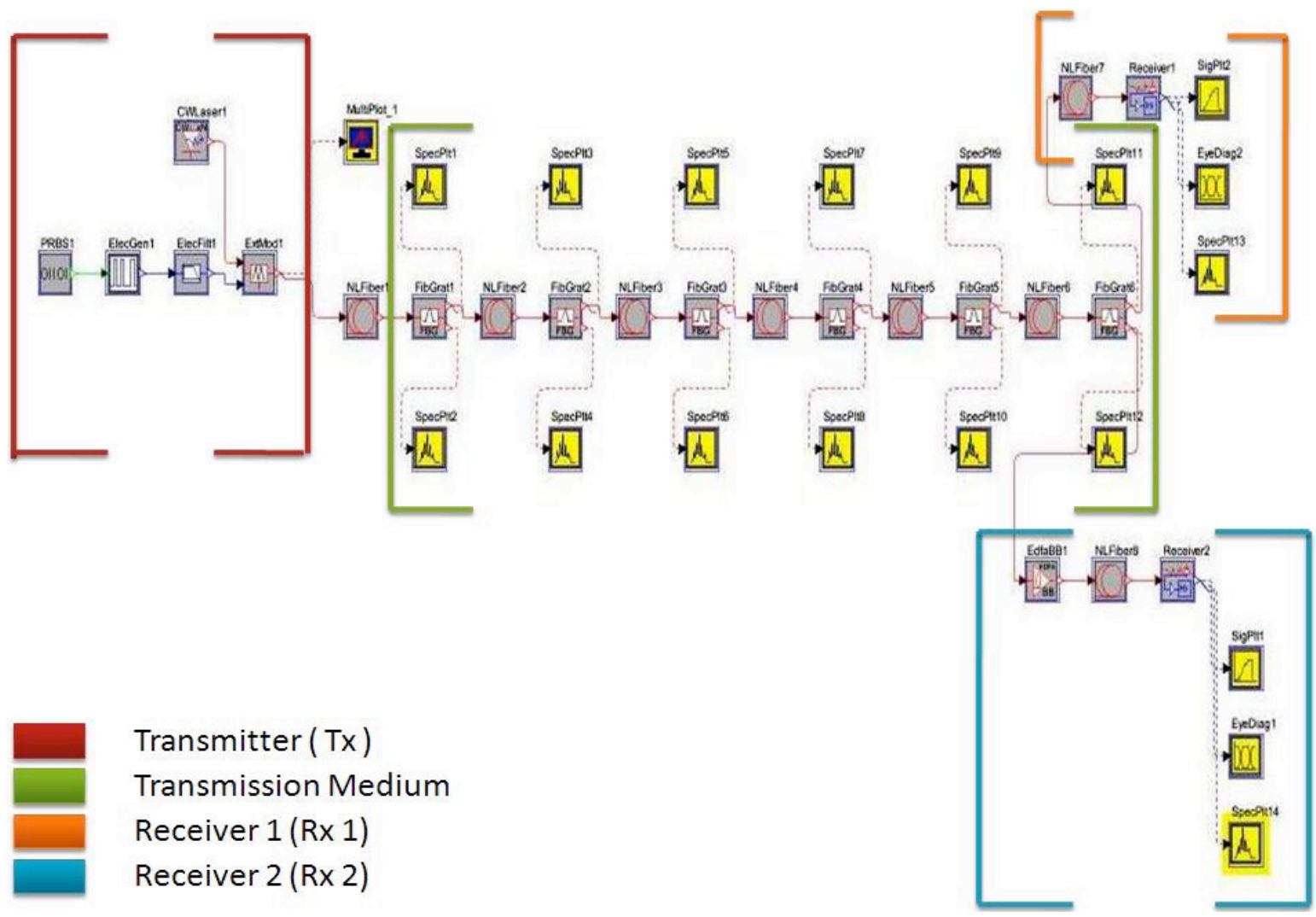

Fig. 8: Array-based FBG sensing system

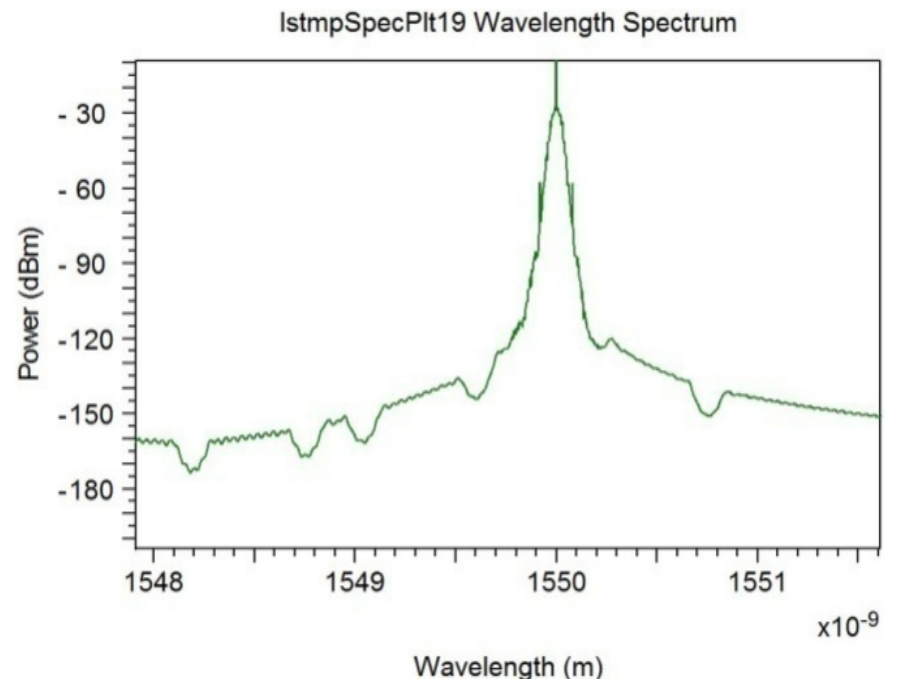

Fig. 9: Transmission pulse for array $\mathrm{FBG}$ sensor at $40^{\circ} \mathrm{C}$

Single FBG sensor: The graph in Fig. 11 shows the Bragg wavelength obtained as a function of temperature. Regression analyses was carried out, with the calculated Line-Of-Best-Fit (LOBF) added. From the software, the value of the linear regression coefficient here was 0.9993 . This value is very close to the value of 1 , where the ideal linear graph with no error would exist. The sensitivity of the model system was estimated to be around $8.30 \mathrm{pm} /{ }^{\circ} \mathrm{C}$. This was quite close to the real value of the FBG sensor from the datasheet, which was $11 \mathrm{pm} /{ }^{\circ} \mathrm{C}$. The Root Mean Square (RMS) error value has also been estimated using Eq. (2) below. The temperature accuracy was inferred from this by dividing this value of the RMS error by the 


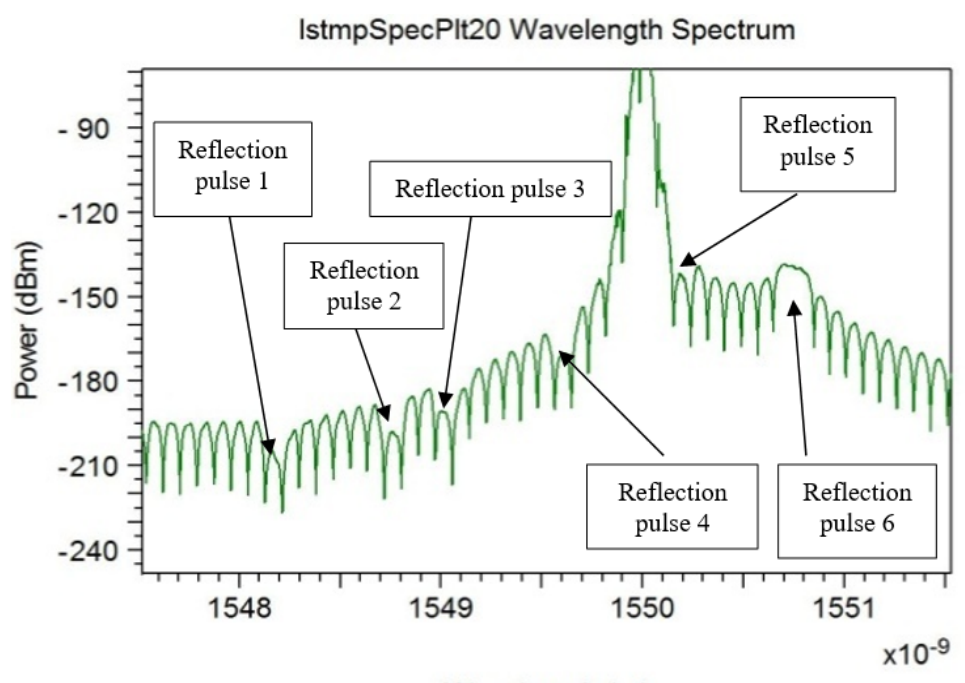

Wavelength $(\mathrm{m})$

Fig. 10: Reflected pulse for array $\mathrm{FBG}$ sensor at $40^{\circ} \mathrm{C}$

\begin{tabular}{llll}
\multicolumn{3}{l}{ Table 2: Analysis for the array } \\
\hline FBGs & $\begin{array}{l}\text { Regression } \\
\text { linear }\end{array}$ & $\begin{array}{l}\text { Sensitivity } \\
\left(\mathrm{pm} /{ }^{\circ} \mathrm{C}\right)\end{array}$ & Linear equation \\
\hline FBG1 & 0.9997 & 8.13 & $\mathrm{y}=8.13 \mathrm{p} x-0.1117 \mathrm{n}$ \\
FBG2 & 0.9992 & 8.20 & $\mathrm{y}=8.20 \mathrm{p} x-0.0696 \mathrm{n}$ \\
FBG3 & 0.9995 & 8.20 & $\mathrm{y}=8.20 \mathrm{p} x-0.2854 \mathrm{n}$ \\
FBG4 & 0.9993 & 8.10 & $\mathrm{y}=8.10 \mathrm{p} x-0.1931 \mathrm{n}$ \\
FBG5 & 0.9993 & 8.20 & $\mathrm{y}=8.20 \mathrm{p} x-0.1392 \mathrm{n}$ \\
FBG6 & 0.9991 & 8.30 & $\mathrm{y}=8.30 \mathrm{p} x-0.0800 \mathrm{n}$ \\
\hline
\end{tabular}

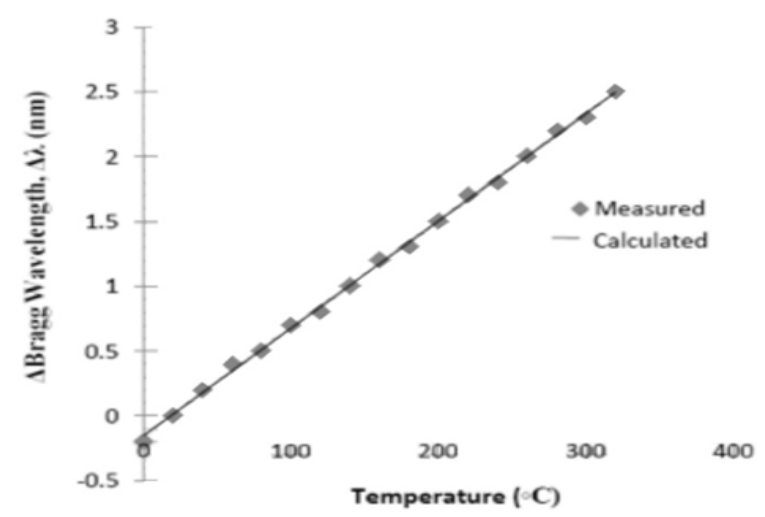

Fig. 11: Graph for Single FBG Sensor

sensitivity of the sensor. Full calculations of error values are shown in Appendix (A):
Root Mean Square Error $=\sqrt{\frac{\sum\left(f\left(x_{i}\right)-y_{i}\right)^{2}}{n}}$

Array FBG sensor: Figure 12 to 17 show data taken for the array. These are summarized in Table 2. Linear regression coefficients were estimated for all six FBGs and were very close to the value of 1 , as expected.

Sensor FBG 1 showed the highest linearity. All sensitivity values were again quite close to $11 \mathrm{pm} /{ }^{\circ} \mathrm{C}$. The linear equations in Table 2 above were used to determine the calculated values (as opposed to measured values) of temperature. These values therefore allowed us to estimate the errors on each sensor over the full range. A full error analyses for the array is shown in Appendix (B). Table 3 shows an analysis comparison between the two types of sensing systems.

\section{CONCLUSION}

OptSim software has been used to design and simulate two types of FBG-based sensing systems; a single FBG sensor and an array type, the latter used to detect temperature at selective and multiple points. The

Table 3: Analysis comparison between single FBG sensor and array-based FBG sensor systems

\begin{tabular}{lll}
\hline FBG sensor characteristics & Single FBG Sensor & Array-based FBG sensors system \\
\hline Description of model system & Used single FBG as a sensor & $\begin{array}{l}\text { Use Multiple of FBG that put in array and in } \\
\text { series or parallel }\end{array}$ \\
Number of Sensor (FBG) & 1 & 6 \\
Detection & Can detect parameter (i.e., temperature) at one & Can detect parameter (i.e., temperature) at \\
& point only & $1548-1550.5$ \\
Center Wavelength & 1550 & $0.9994(\mathrm{mean})$ \\
Regression & 0.9993 & $8.30 \mathrm{pm} /{ }^{\circ} \mathrm{C}(\mathrm{mean})$ \\
Sensitivity & $8.30 \mathrm{pm} /{ }^{\circ} \mathrm{C}$ & $\pm 0.66^{\circ} \mathrm{C}(\mathrm{mean})$ \\
Temperature Accuracy & $\pm 1.32^{\circ} \mathrm{C}$ & $\mathrm{High}$ \\
Resolution & Low & $6 \mathrm{~km}$ \\
Length & $1 \mathrm{~km}$ &
\end{tabular}




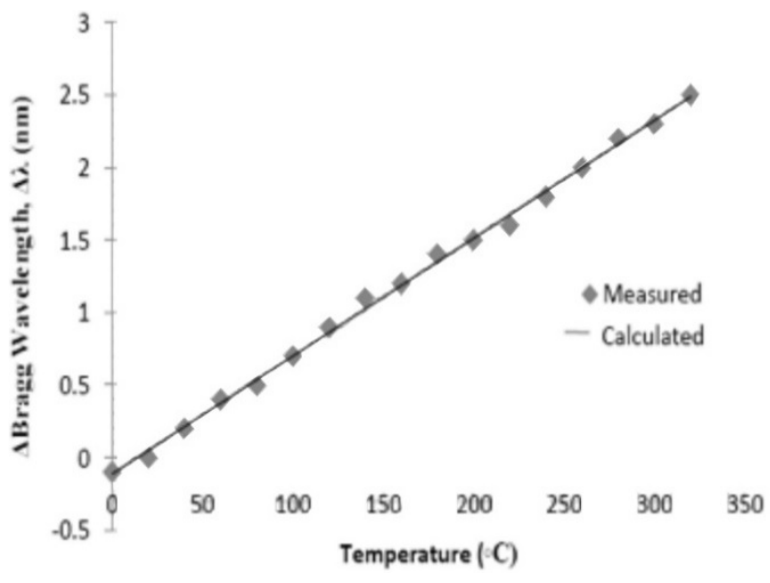

Fig. 12: Graph for FBG 1

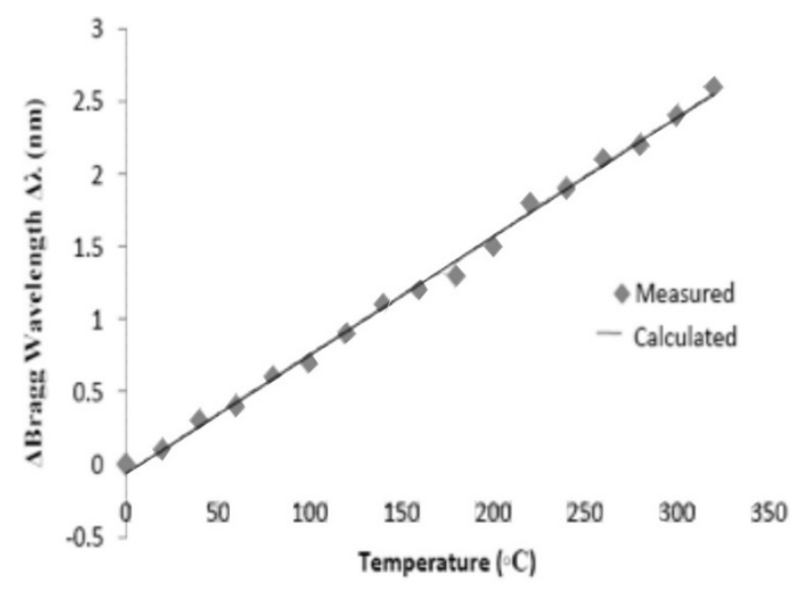

Fig. 13: Graph for FBG 2

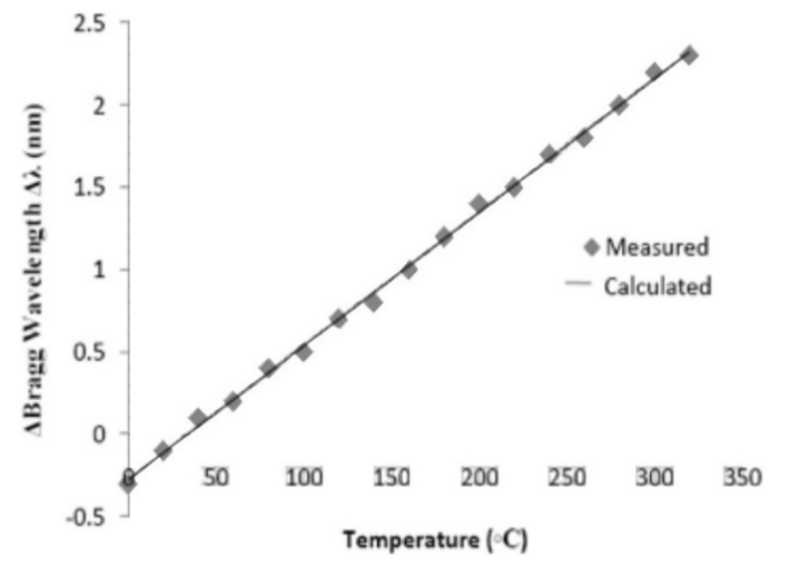

Fig. 14: Graph for FBG 3

RMS error of the temperature accuracy for the single FBG sensor was found to be $1.32^{\circ} \mathrm{C}$ and for the array based sensor $0.66^{\circ} \mathrm{C}$ on average, both having a dynamic range from 0 to $320^{\circ} \mathrm{C}$. The array-based $\mathrm{FBG}$ sensor system therefore showed $50 \%$ greater accuracy than the single FBG sensor.

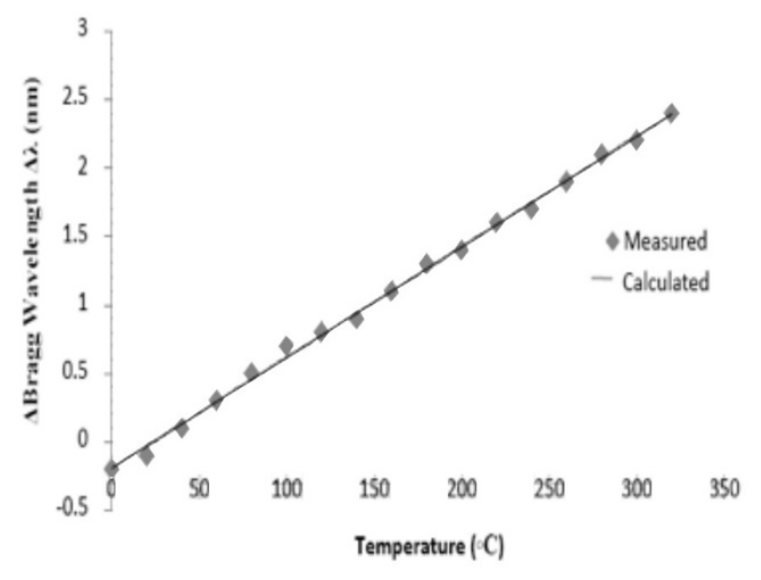

Fig. 15: Graph for FBG 4

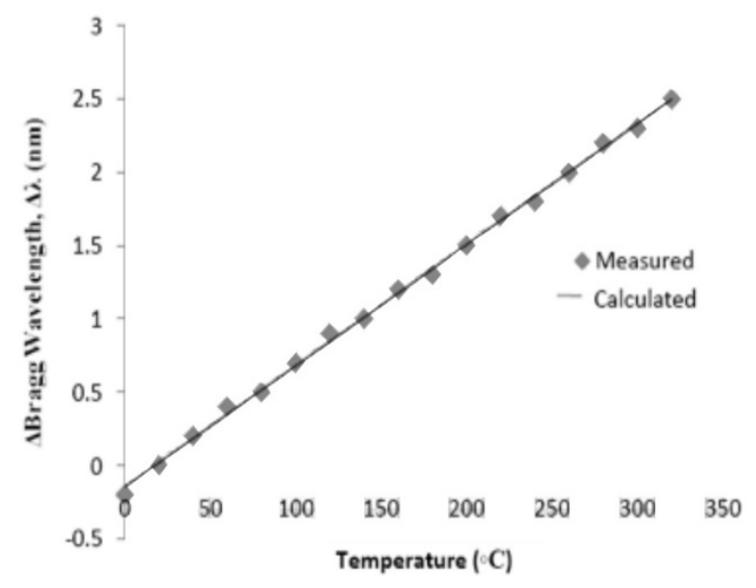

Fig. 16: Graph for FBG 5

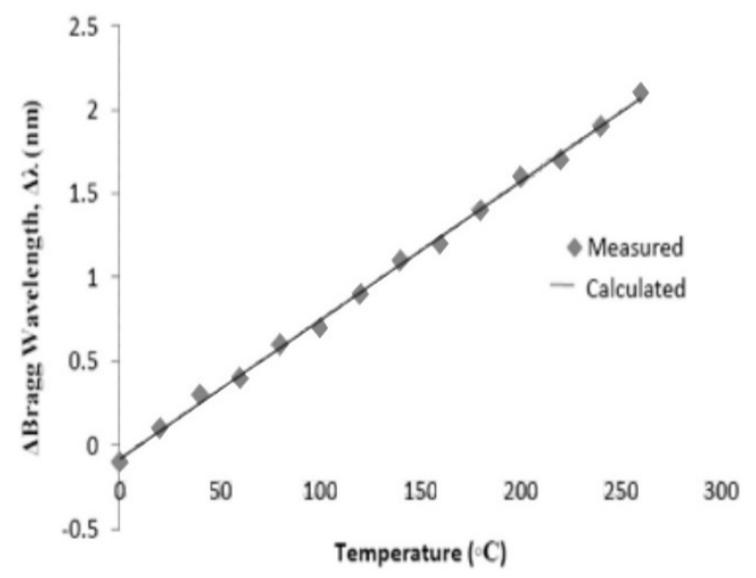

Fig. 17: Graph for FBG 6

\section{ACKNOWLEDGMENT}

The authors wish to acknowledge the administration of Qaiwan International University and Universiti Teknologi Malaysia (UTM) for their financial support. We would also like to show our 
Res. J. Appl. Sci. Eng. Technol., 16(5): 212-220, 2019

appreciation towards the Photonics Technology Center (PTC) and Faculty of Electrical Engineering at UTM for providing us with the facilities and software to accomplish this study.

Appendix (A): Single FBG Sensor

Table 4: Estimate for root-mean-square (RMS) error of single FBG sensor:

\begin{tabular}{lcccc}
\hline Temperature $\left({ }^{\circ} \mathrm{C}\right)$ & $y$ (simulated/measured) $(\mathrm{nm})$ & $y$ (calculated) $(\mathrm{nm})$ & Error & Error $^{2}$ \\
\hline 0 & -0.2 & -0.1549 & 0.0451 & 0.00203400 \\
20 & 0 & 0.0111 & 0.0111 & 0.00012321 \\
40 & 0.2 & 0.1771 & -0.0229 & 0.00052441 \\
60 & 0.4 & 0.3431 & -0.0569 & 0.00323760 \\
80 & 0.5 & 0.5091 & 0.0091 & 0.00008281 \\
100 & 0.7 & 0.6751 & -0.0249 & 0.00062001 \\
120 & 0.8 & 0.8411 & 0.0411 & 0.00168920 \\
140 & 1.0 & 1.0071 & 0.0071 & 0.00005041 \\
160 & 1.2 & 1.1731 & -0.0269 & 0.00072361 \\
180 & 1.3 & 1.3391 & 0.0391 & 0.00152880 \\
200 & 1.5 & 1.5051 & 0.0051 & 0.00002601 \\
220 & 1.7 & 1.6711 & -0.0289 & 0.00083521 \\
240 & 1.8 & 1.8371 & 0.0371 & 0.00137640 \\
260 & 2.0 & 2.0031 & 0.0031 & 0.00000961 \\
280 & 2.2 & 2.1691 & -0.0309 & 0.00095481 \\
300 & 2.3 & 2.3351 & 0.0351 & 0.00123200 \\
320 & 2.5 & 2.5011 & 0.0011 & 0.00000121 \\
& & & & sum $=2.0340 \mathrm{e}-3$ \\
\hline
\end{tabular}

By referring to Table 4, we can estimate the value of the RMS error for the single FBG sensor.

Root Mean Square Error $=\sqrt{\frac{\sum\left(f\left(x_{i}\right)-y_{i}\right)^{2}}{n}}$

where,

$\mathrm{f}\left(\mathrm{x}_{\mathrm{i}}\right) \quad=$ Mean of estimated error

$\mathrm{y}_{\mathrm{i}} \quad=$ Estimate of error

$\mathrm{n} \quad=$ Number of data (17)

Using the formula in Eq. (3), the calculation is:

$$
R M S \text { for Single } F B G=\sqrt{\frac{2.0340 \mathrm{e}-3}{17}}= \pm 0.01094 \mathrm{~nm}\left(\text { sensitivity }=8.30 \mathrm{pm} /{ }^{\circ} \mathrm{C}\right)
$$

Therefore the estimated temperature accuracy of the single $\mathrm{FBG}$ sensor over the range $0-320^{\circ} \mathrm{C}=\mathrm{RMS}$ error/sensitivity for single $\mathrm{FBG}$

$$
=\underline{1.318 \operatorname{deg} \mathrm{C}}
$$

Appendix (B): Array-based FBG sensor

\begin{tabular}{|c|c|c|c|c|c|c|}
\hline \multirow[b]{2}{*}{ Temp.(deg C) } & \multicolumn{6}{|c|}{ Estimate error (Ycalculated- Ymeasured) (nm) } \\
\hline & FBG 1 & FBG 2 & FBG 3 & FBG 4 & FBG 5 & FBG 6 \\
\hline 0 & -0.0117 & -0.0696 & 0.0146 & 0.0069 & 0.0608 & 0.0200 \\
\hline 20 & 0.0509 & -0.0056 & -0.0214 & 0.0689 & 0.0248 & -0.0140 \\
\hline 40 & 0.0135 & -0.0416 & -0.0574 & 0.0309 & -0.0112 & -0.0480 \\
\hline 60 & -0.0239 & 0.0224 & 0.0066 & -0.0071 & -0.0472 & 0.0180 \\
\hline 80 & 0.0387 & -0.0136 & -0.0294 & -0.0541 & 0.0168 & -0.0160 \\
\hline 100 & 0.0013 & 0.0504 & 0.0346 & -0.0831 & -0.0192 & 0.0500 \\
\hline 120 & -0.0361 & 0.0144 & -0.0014 & -0.0211 & -0.0552 & 0.0160 \\
\hline 140 & -0.0735 & -0.0216 & 0.0626 & 0.0409 & 0.0088 & -0.0180 \\
\hline 160 & -0.0109 & 0.0424 & 0.0266 & 0.0029 & -0.0272 & 0.0480 \\
\hline 180 & -0.0483 & 0.1064 & -0.0094 & -0.0351 & 0.0368 & 0.0140 \\
\hline 200 & 0.0143 & 0.0704 & -0.0454 & 0.0269 & 0.0008 & -0.0200 \\
\hline 220 & 0.0769 & -0.0656 & 0.0186 & -0.0111 & -0.0352 & 0.0460 \\
\hline 240 & 0.0395 & 0.0016 & -0.0174 & 0.0509 & 0.0280 & 0.0120 \\
\hline 260 & 0.0021 & -0.0376 & 0.0466 & 0.0129 & -0.0072 & -0.0220 \\
\hline 280 & -0.0353 & 0.0264 & 0.0106 & -0.0251 & -0.0432 & \\
\hline 300 & 0.0273 & -0.0096 & -0.0254 & 0.0369 & 0.0208 & \\
\hline 320 & 0.0101 & -0.0456 & 0.0386 & -0.0011 & -0.0152 & \\
\hline
\end{tabular}

Table 5: Estimate for root-mean-square (RMS) error of array FBG sensor 
By referring to Table 5, we can estimate the value of the RMS error for each FBG sensor. These calculations were the same as for the single FBG (i.e., in each case).

$\underline{\text { FBG } 1}$

$$
\begin{aligned}
& \text { RMS error }=\sqrt{\frac{1.3689 e-4}{17}}=0.0028377 \mathrm{~nm} \\
& \text { Temperature accuracy }=\text { RMS error } / \text { sensitivity (sensitivity }=8.30 \mathrm{pm} /{ }^{\circ} \mathrm{C} \text { ) } \\
& = \pm 0.349^{\circ} \mathrm{C}
\end{aligned}
$$

$\underline{\text { FBG } 2}$

RMS error $=\sqrt{\frac{4.8442 e-3}{17}}=0.0168805 \mathrm{~nm}$

Temperature accuracy $=$ RMS error $/$ sensitivity $\left(\right.$ sensitivity $\left.=8.30 \mathrm{pm} /{ }^{\circ} \mathrm{C}\right)$ $= \pm 2.0338^{\circ} \mathrm{C}$

$\underline{\text { FBG } 3}$

RMS error $=\sqrt{\frac{2.1316 e-4}{17}}=0.0035410 \mathrm{~nm}$

Temperature accuracy $=$ RMS error $/$ sensitivity $\left(\right.$ sensitivity $=8.30 \mathrm{pm} /{ }^{\circ} \mathrm{C}$ ) $= \pm 0.42663^{\circ} \mathrm{C}$

$\underline{\text { FBG } 4}$

RMS error $=\sqrt{\frac{4.7610 e-5}{17}}=0.002608 \mathrm{~nm}$

Temperature accuracy $=$ RMS error/sensitivity $\left(\right.$ sensitivity $\left.=8.30 \mathrm{pm} /{ }^{\circ} \mathrm{C}\right)$ $= \pm 0.31422^{\circ} \mathrm{C}$

FBG 5

RMS error $=\sqrt{\frac{3.6966 e-3}{17}}=0.0016735 \mathrm{~nm}$

Temperature accuracy $=$ RMS error $/$ sensitivity $\left(\right.$ sensitivity $\left.=8.30 \mathrm{pm} /{ }^{\circ} \mathrm{C}\right)$ $= \pm 0.20163^{\circ} \mathrm{C}$

$\underline{\text { FBG } 6}$

RMS error $=\sqrt{\frac{4.0000 e-4}{14}}=0.0053452 \mathrm{~nm}$

Temperature accuracy $=$ RMS Error $/$ sensitivity $\left(\right.$ sensitivity $\left.=8.30 \mathrm{pm} /{ }^{\circ} \mathrm{C}\right)$ $= \pm 0.644^{\circ} \mathrm{C}$

Therefore the average estimated temperature accuracy for the complete array-based FBG sensor over the range $0-320^{\circ} \mathrm{C}$ is given by

RMS FBG1 + ..$+\mathrm{FBG} 6 /= \pm \underline{0.66155^{\circ}} \underline{\mathrm{C}}$.

\section{REFERENCES}

Culshaw, B., 1989. Optical Fiber Sensors: Systems and Applications. Artech House Publishers, Norwood, MA, Vol. 2.

Gebremichael, Y.M., B.T. Meggitt, W.J.O. Boyle, W. Li, K.T.V. Grattan, L. Boswell, B. McKinley, K.A. Aarnes and L. Kvenild, 2001. Multiplexed fibre bragg grating sensor system for structural integrity monitoring in large civil engineering applications. Proceedings of Sensors and their Applications XI, (IOP Publishing Ltd., London), pp: 341-345.

Gerd, K., 2000. Optical Fiber Communications. 3rd Edn., McGraw Hill, pp: 243-379.

John Dakin, B.C., 1997. Optical Fiber Sensors: Applications, Analysis and Future Trends. Artech House Publishers, Norwood, MA, IV: 377.

Joseph, C.P., 2005. Fiber OpticCommunication. 5th Edn., Prentice Hall, Upper Saddle River, N.J.
Kersey, A.D., M.A. Davis, H.J. Patrick, M. LeBlanc, K.P. Koo, C.G. Askins, M.A. Putnam and E.J. Friebele, 1997. Fiber grating sensors. J. Lightwave Technol., 15(8): 1442-1463.

Kersey, A.D., T.A. Berkoff and W.W. Morey, 1993. Multiplexed fiber Bragg grating strain-sensor system with a fiber Fabry-Perot wavelength filter. Opt. Lett., 18(16): 1370-1372.

Othonos, A., 2000. Fiber Bragg Gratings, in Optical Fiber Sensor Technology: Advanced Applications. In: Grattan, K.T.V. and B.T. Meggitt (Eds.), Kluwer Academic Publishers, Dorsrecht, Netherlands, pp: 113-115.

Rao, Y.J., 1997. In-fibre bragg grating sensors. Meas. Sci. Technol., 8(04): 355.

Rao, Y.J., D.J. Webb, D.A. Jackson, L. Zhang and I. Bennion, 1997. In-fiber Bragg-grating temperature sensor system for medical applications. J. Lightwave Technol., 15(5): 779-785. 